\title{
GxE evaluation of salinity tolerant barley genotypes by AMMI model
}

\author{
R.P.S. Verma ${ }^{1}$, A.S. Kharab, Vishnu Kumar and Ajay Verma* \\ Indian Institute of Wheat and Barley Research, \\ Karnal-132 001, India.
}

Received: 21-03-2016

Accepted: 25-05-2016

DOI: $10.18805 /$ asd.v36i3.11444

\section{ABSTRACT}

The highly significant variances due to interaction, environments and genotypes were observed by AMMI analysis of salinity tolerant barley genotypes under multi location trials. The genotypes G6 and G13 with negative IPCA1 values showed positive IPCA2, IPCA3, IPCA4 values. Genotype G1 showed lowest value of D with smallest negative IPCA1 score (-0.013). Genotype G18 followed by G8, G1 and G5 were the stable performer based on ASV. Yield stability index advocated G8 followed by G5, G10, G4 and G12. The results of MASV indicated that genotypes G5, G1, G15, G17, G9 and G19 were stable, whereas genotypes G5, G9, G8 and G11 were the stable genotypes with relatively more average yield. Overall mean ranks of all of the AMMI estimates, genotypes G5, G1 and G8 were the most stable genotypes followed by genotypes G17 and G18.

Key words : AMMI models, AMMI stability value (ASV), D(AMMI distance), Modified AMMI stability value (MASV), Yield stability index(YSI)

\section{INTRODUCTION}

The low productivity of cereal crops due to salinisation of cultivable land had attracted the attention of policy makers. Total area of saline soils and sodic soils at global level were estimated by FAO up to 397 and 434 million hectare, respectively. The increasing population of world often led to the use of marginal salt affected soils (Verma et al., 2011). Barley is known to be one of the most salt tolerant crops having high level of variability in tolerance among cultivars (Kharab et al., 2013). Soil salinity is a major abiotic stress which not only delays but also reduces flowering and yield for barley crops (Kumar et al., 2014). To mitigate this problem, one of the cheap alternatives is to grow salinity tolerant varieties. The continuous efforts of barley workers under coordinated system have resulted in the development and release of tolerant varieties. These varieties produce good yield under unfavorable conditions (Anonymous 2014).

Genotype by environment interaction $(\mathrm{GxE})$ refers to the differential responses of genotypes across environments (Bavandpori et al., 2015). The repeatable GxE interactions, change the ranking of genotypes across environments, are meaningful for the specific breeding strategy (Sabaghnia et al., 2008). Several statistical models have been used to understand interactions of different crops for identifying suitable genotypes (Bose et al., 2014). Usually for multi location trials analysis of variance (ANOVA), principal component analysis (PCA) and linear regression (LR) analysis methods are used (Mohammadi et al., 2010). The additive main effects and multiplicative interaction
(AMMI) model, describes interaction effects more effectively (Mortazavian et al., 2014). Kandus et al. (2010) found the AMMI model was the best model to describe the GxE interaction in maize cereal. Mohammadi et al (2015) established the more usefulness of AMMI analysis for durum wheat genotypes. The main objectives of the present investigation was to study (i) stratification of salinity tolerant barley genotypes based on interaction effects by AMMI estimates (ii) to compare the ranking of genotypes by various methods (iii) to identify similar or redundant measures to streamline GxE interaction analysis in MET data.

\section{MATERIALS AND METHODS}

The AMMI model is defined for main effects and GxE interaction effects as per Silveira et al., 2013:

$Y_{i j}=\mu+$ gi. $+\mathrm{e} . \mathrm{j}+\sum_{\mathrm{kk}=1}^{\mathrm{n}} \lambda_{\mathrm{k}} \gamma_{\mathrm{ik}} \delta_{j k}+\rho_{i j}$

where $Y_{i j}$ is the yield of the $i$-th genotype in the $j$-th environment; $\mu$ is the grand mean; gi. and e.j are the genotype and environment deviations from the grand mean, respectively; $\lambda_{k}$ is the eigen value of the Principal Component analysis axis $\mathrm{k} ; \gamma_{\mathrm{ik}}$ and $\delta_{\mathrm{jk}}$ are the genotype and environment principal component scores (eigenvectors) for axis $\mathrm{k}$; $\mathrm{n}$ is the number of principal components retained in the model and $\rho_{\mathrm{ij}}$ is the error term.

\section{AMMI Stability Value (ASV)}

The ASV is the distance from the coordinate point to the origin in a two-dimensional scatter graph of IPCA1 scores against IPCA2 scores in the AMMI model (Purchase et al., 2000). Because the IPCA1 score contributes more to 
the GxE interaction sum of squares, a weighted value is needed. This weight is calculated for each genotype and environment according to the relative contribution of IPCA1 to IPCA2 to the interaction SS as follows:

AMMI Stability Value $($ ASV $)=$

$$
\sqrt{\left[\frac{\text { SSIPCA1 }}{\text { SSIPCA2 }} * \text { IPCA1 score }\right]^{2}+\text { IPCA2 score }{ }^{2}}
$$

where SSIPCA 1 and SSIPCA2 are sum of squares by the IPCA1, IPCA2 respectively and the weight given to the IPCA1value by dividing the IPCA1 sum of squares by the IPCA2 sum of squares. The larger the IPCA score, either negative or positive, the more specifically adapted a genotype is to certain environments. Smaller IPCA scores indicate a more stable genotype across environments. Similarly, IPCA2 score near to zero revealed more stable, while large values indicated more responsive and less stable genotypes.

\section{Modified AMMI's stability value (MASV)}

Adugna and Labuschange had introduced in the year 2002 new parameter as modified AMMI's stability value for effective interpretation of GE interactions as follows:

MASV $=\sqrt{\sum_{\mathrm{n}=1}^{\mathrm{N}-1}\left(\frac{\operatorname{SSIPC}_{\mathrm{n}}}{\operatorname{SSIPC}_{\mathrm{n}+1}}\right)\left(\mathrm{IPC}_{\mathrm{n}}^{2}\right)+\left(\mathrm{IPC}_{\mathrm{n}+1}^{2}\right)}$

In this modified AMMI stability parameter, all significant IPCs were used.

The AMMI distance statistic coefficient (D) (Zhang et al., 1998) was calculated as the distance of the interaction principal component (IPC) from the origin

AMMI Distance $\left(D_{\mathrm{i}}\right)=\sqrt{\sum_{\mathrm{i}=1}^{\mathrm{n}} \gamma_{\mathrm{i} s}^{2}} \quad(\mathrm{i}=1,2,3, . \mathrm{n})$
Yield stability index (YSI) considered the rank of yield of genotypes across environments and rank of AMMI stability value. This index incorporate mean and stability index in a single criteria and calculated as (Farshadfar et al., 2011):

$\mathrm{YSI}=\mathrm{RASV}+\mathrm{RY}$

where, RASV is the rank of AMMI stability value and RY is the rank of mean yield of genotypes (RY) across environments.

Twenty barley genotypes were evaluated during crop season 2013-14 across 6 environments viz: Hisar, Faizabad-1, Faizabad-2, Rampura, Bawal and DWR-Hisar. The details of pedigrees for evaluated genotypes along with environmental conditions are presented in Table 1. The randomized complete block design employed with four replications for field experimentation. Recommended agronomical practices were carried out to harvest the good yield. AMMI and correlation analysis were carried out by Genstat software version 17.1 (VSN international).

\section{RESULTS AND DISCUSSION}

The yield of the 20 genotypes tested over the six environments indicated highly significant effects due to genotypes $(\mathrm{G})$, environments $(\mathrm{E})$ and the $\mathrm{G} \times \mathrm{E}$ interaction (Table 2). The environmental main effect (E) emerged as the most important source of variation due to its largest contribution $(54.4 \%)$ to the total sum of squares (TSS). The contribution of GxE interaction to the TSS was observed to be $21.9 \%$ which was more than main effects of genotypes $(7.67 \%)$. This indicates the differences in yield and rank of genotypes was largely due to environmental effect (Abdipur

Table 1: Details of salinity tolerant barley genotypes, parentage and environmental conditions

\begin{tabular}{|c|c|c|c|c|c|c|}
\hline Code & Genotype & Parentage & Code & Environment & Latitude & Longitude \\
\hline $\mathrm{G} 1$ & NDB1592 & IBCB-S(2008-09)-31 & E1 & Hisar & $29^{\circ} 10^{\prime} \mathrm{N}$ & $75^{\circ} 46^{\prime} \mathrm{E}$ \\
\hline $\mathrm{G} 2$ & KB 1370 & JYOTI/RD2552 & E2 & Faizabad-1 & $26^{\circ} 87^{\prime} \mathrm{N}$ & $80^{\circ} 97^{\prime} \mathrm{E}$ \\
\hline G3 & RD 2552 & RD2035/DL472 & E3 & Faizabad-2 & $26^{\circ} 87^{\prime} \mathrm{N}$ & $80^{\circ} 97^{\prime} \mathrm{E}$ \\
\hline G4 & DWRB 131 & IBYT-LRA-M -11 (2011 -12) & E4 & Rampura & $24^{\circ} 46^{\prime} \mathrm{N}$ & $75^{\circ} 44^{\prime} \mathrm{E}$ \\
\hline G5 & NDB 1586 & (1BYT-MRA-24-2008-09) & E5 & Bawal & $28^{\circ} 10^{\prime} \mathrm{N}$ & $76^{\circ} 59^{\prime} \mathrm{E}$ \\
\hline G6 & RD 2886 & RD2715 / K750 // PETUNIA- 1 & E6 & DWR- Hisar & $29^{\circ} 17^{\prime} \mathrm{N}$ & $75^{\circ} 67^{\prime} \mathrm{E}$ \\
\hline G7 & NDB 1173 & BYTLRA 3-(1 994-95)/NDB217 & & & & \\
\hline G8 & RD 2888 & RD2683/RD2503//RD2683 & & & & \\
\hline G9 & BH 984 & 2005EIBGN-4/BH646 & & & & \\
\hline G10 & BH 972 & 29"' EIBGN-22/BH 646 & & & & \\
\hline G11 & RD 2860 & RD2552/ADABELLA/M-1 11 /CANELA & & & & \\
\hline G12 & RD 2889 & RD2552 /UBL-9//GLORIA-BAR & & & & \\
\hline G13 & RD 2890 & $\mathrm{BH} 393 / \mathrm{RD} 2360 / / \mathrm{RD} 2715$ & & & & \\
\hline G14 & RD 2887 & R D2670/RD2683// BLLU / PINON & & & & \\
\hline G15 & NDB 1600 & NDB2OB/ALFA93 & & & & \\
\hline G16 & BH 986 & RD2670/K792 & & & & \\
\hline G17 & BH 985 & JB47/K792 & & & & \\
\hline G18 & RD 2794 & RD2035/RD2683 & & & & \\
\hline G19 & NDB 1587 & IBON-HI-31(2008-09) & & & & \\
\hline G20 & KB 1375 & K551/HUB158 & & & & \\
\hline
\end{tabular}


Table 2: AMMI analysis of salinity tolerant barley genotypes over locations

\begin{tabular}{|c|c|c|c|c|c|c|}
\hline $\begin{array}{l}\text { Source of } \\
\text { variation }\end{array}$ & $\begin{array}{l}\text { Degree of } \\
\text { freedom }\end{array}$ & $\begin{array}{l}\text { Sum of } \\
\text { squares }\end{array}$ & $\begin{array}{l}\text { Mean Sum } \\
\text { of squares }\end{array}$ & $\begin{array}{c}\text { Variance } \\
\text { ratio }\end{array}$ & $\%$ TSS & $\% \mathrm{GxE}$ \\
\hline Treatments & 119 & 33233 & 279.3 & $18.33^{* * *}$ & 84.02 & \\
\hline Genotypes & 19 & 3035 & 159.7 & $10.49 * * *$ & 7.67 & \\
\hline Environments & 5 & 21519 & 4303.7 & $69.58 * * *$ & 54.40 & \\
\hline Block & 18 & 1113 & 61.8 & $4.06 * * *$ & & \\
\hline Interactions & 95 & 8680 & 91.4 & $6.00 * * *$ & 21.94 & \\
\hline IPCA 1 & 23 & 3893 & 169.3 & 11.11 & & 44.85 \\
\hline IPCA 2 & 21 & 2173 & 103.5 & 6.79 & & 25.03 \\
\hline IPCA 3 & 19 & 1499 & 78.9 & 5.18 & & 17.27 \\
\hline IPCA 4 & 17 & 729 & 42.9 & 2.82 & & 8.40 \\
\hline Residuals & 15 & 386 & 25.7 & 1.69 & & \\
\hline Error & 342 & 5209 & 15.2 & & & \\
\hline Total & 479 & 39556 & 82.6 & & & \\
\hline
\end{tabular}

\%TSS, percentage of total sum of squares, \% GxE, percentage of GxE total sum of squares

*** denotes significant at 0.001 level of significance

and Vaezi, 2014). Partitioning of GxE interaction indicated the AMMI4 model described the interaction patterns significantly by the first four IPCA's based on crossvalidation. The first four principal component axes of the interaction captured $44.8 \%, 25.0 \%, 17.3 \%$ and $8.4 \%$ of the interaction sum of squares.

Average yield: The range for yield in the present investigation varied from minimum of 19.8 to $33.5 \mathrm{q} / \mathrm{ha}$ with genotype NDB 1173 recorded the highest yield followed by RD 2888 and BH 972 (Table 3). Genotypes with lower yield were observed as KB 1375, BH 986 and KB 1370. The magnitude of the genotype $\mathrm{x}$ environment interaction sum of squares was less than that for environments indicated substantial differences in environments as compared to $\mathrm{GxE}$ interaction toward genotypes.

Crossover and non-crossover IPCAs interactions: IPCA scores of genotypes showed both positive and negative values. Nine out of 20 genotypes showed negative IPCA1 score with some environments as well as showed positive interactions with other environments. Genotypes with negative IPCA1 score i.e G1(NDB 1592), G6(RD 2886), G13(RD 2890), G14(RD 2887) showed positive IPCA4 values (Table 3). The genotypes G6(RD 2886), G13(RD 2890) with lower IPCA1 scores showed positive IPCA2, IPCA3, IPCA4 values respectively. These genotypes would produce a lower absolute $\mathrm{G} \times \mathrm{E}$ interaction effect and had less variable yields (more stable).

AMMI stability index (D): The ranking of genotypes in ascending order of ' $D$ ' values were those in G1 (0. 97) < G5 $(1.11)<$ G15 (1.42) < G17 (1.47). Genotypes with lowest yield G20(KB 1375) and G16(BH 986) exhibited D values 2.06 and 2.09, respectively. Genotype G1(NDB 1592) showed lowest value of $D$ and smaller negative IPCA1 score (-0.013). This genotype recognized as possessing stable yield of lowest magnitude for studied environments.
AMMI stability value (ASV): In ASV method, a genotype with least ASV score is the most stable. Accordingly genotypes G18 (RD 2794) followed by G8(RD 2888), G1(NDB1592) and G5(NDB 1586) were the most stable, while genotypes G6(RD 2886), G13(RD 2890), G3(RD 2552) and G14(RD 2887) would be undesirable.

Yield Stability index (YSI): Genotypes with least YSI are considered as the stable with high yield. The most desirable genotype for selection of both stability and high yield was G8(RD 2888) followed by G5(NDB 1586), G10(BH 972), (G4(DWRB 131) and G12(RD 2889).

Modified AMMI stability value (MASV): The visual interpretation of GxE interaction through biplot is not valid for situations with more than two significant IPCs (Gauch, 2006). The AMMI model in this study indicated that there was a more complex interaction of GxE and it could not facilitate graphical visualization of the genotypes in low dimensions and so it is essential to use an alternative procedure to interpretation of GE interaction using AMMI parameters (Sabaghnia et al., 2012).

Although, ASV parameter was reported to produce a balanced measurement as parameter uses IPC1 and IPC2 scores as well as magnitude of their sum of squares and so is different from the other AMMI parameters which use only genotypic or environmental IPCs scores or their modifications (Sabaghnia et al., 2012). The modified AMMI's stability value (MASV) used all four significant IPCs. The results of MASV indicated that genotypes G5, G1, G15, G17, G9,G19, G16, G5, G14, G8 and G11 were most stable, whereas genotypes G5, G9, G8 and G11 were the stable genotypes which had relatively more average yield (Table 3). Therefore, MASV parameter introduced some of the high mean yielding genotypes (G5 and G9) as the most stable ones. As per AMMI estimates computed from four significant IPCs were more useful and introduced relatively 


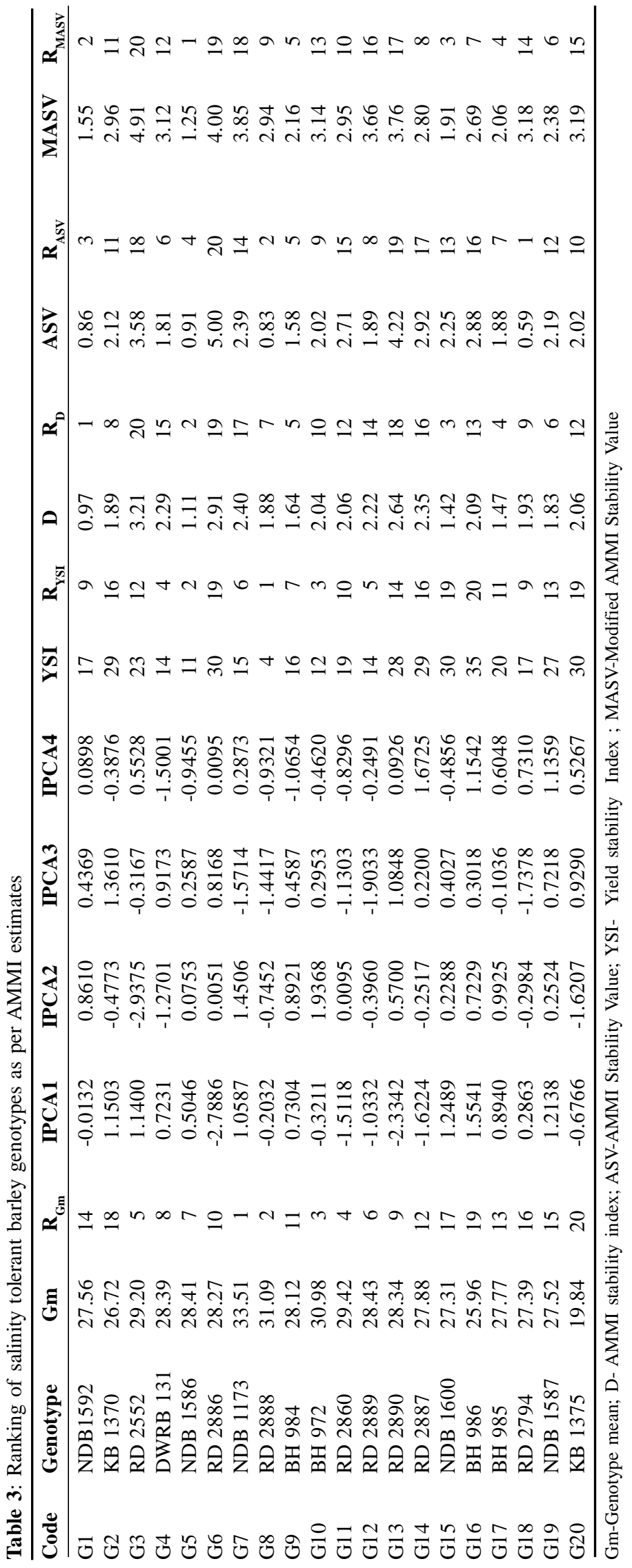


the high yielding genotypes as the most stable genotypes. Considering the mean ranks of all of the AMMI stability parameters, genotypes G5, G1 and G8 were the most stable genotypes followed to genotypes G17 and G18. All of these stable genotypes, G5 and G8 had the high mean yield performance over grand mean.

\section{CONCLUSIONS}

The AMMI model has been well established for understanding complex GxE interactions in multienvironmental trials for number of cereal crops. The interaction of 20 salinity tolerant barley genotypes with 6 environments was best predicted by the first four significant principal components of genotypes and environments. The AMMI model used in the present study indicated a more complex GE interaction which required as many as four IPCs. AMMI based parameters assisted breeders to have an overall picture in behavior of the genotypes, the environments and
GxE interaction. The ASV and MASV benefit dynamic concept of stability and could be useful simultaneous selection of yield and stability (Dehghani et al., 2010). The results obtained by AMMI analysis indicated that genotypes G5 (NDB 1586), G1 (NDB1592), G8 (RD 2888) and G17 (BH 985) were as the stable genotypes and would be recommended salinity tolerant barley for saline areas of the country.

\section{ACKNOWLEDGEMENTS}

The support provided by Dr A. Sarkar, ICARDA New Delhi and Dr Murari Singh, Senior Biometrician, ICARDA Jordan sincerely acknowledged by authors. The multi-environment testing of barley genotypes was performed at the All India Coordinated Wheat \& Barley Improvement Programme (AICW\&BIP) centers across the country. Authors are grateful to the staff of AICW\&BIP centers to carry out the field evaluation of barley genotypes.

\section{REFERENCES}

Abdipur M and Vaezi B (2014). Analysis of the genotype-by-environment interaction of winter barley tested in the Rainfed Regions of Iran by AMMI Adjustment. Bulgarian Journal of Agricultural Science. 20: 421-427.

Adugna W and Labuschagne MT (2002). Genotype, environment interactions and phenotypic stability analyses of linseed in Ethiopia. Plant Breed. 121: 66-71.

Anonymous (2014). Progress report of All India coordinated wheat and barley improvement Project 2013-14. Vol. VI. Barley Network. Directorate of Wheat Research, Karnal, India.

Bavandpori F, Ahmadi J and Hossaini S (2015). Yield Stability Analysis of Bread Wheat Lines using AMMI Model. Agricultural Communications. 3: 8-15.

Bose LK, Jambhulkar NN, Pande K and Singh ON (2014). Use of AMMI and other stability statistics in the simultaneous selection of rice genotypes for yield and stability under direct-seeded conditions. Chilean Journal of Agricultural Research. 74:3-9.

Dehghani, H., Sabaghpour SH and Ebadi A (2010). Study of genotype $\times$ environment interaction for chickpea yield in Iran. Agron. J. 102: 1-8.

Farshadfar E, Mahmodi N and Yaghotipoor A (2011). AMMI stability value and simultaneous estimation of yield and yield stability in bread wheat (Triticum aestivum L.). Australian Journal of Crop Science. 5: 1837-1844.

Gauch HG (2006). Statistical analysis of yield trials by AMMI and GGE. Crop Sci. 46: 1488-1500.

Kandus M, Almorza D, Boggio Ronceros R and Salerno JC (2010). Statistical methods for evaluating the genotypeenvironment interaction in maize (Zea mays L.). Phy. Yld. 39-46.

Kharub AS, Verma R P S, Kumar D, Kumar V, Selvakumar R and Sharma I (2013). Dual purpose barley (Hordeum vulgare L) in India: Performance and potential. $J$ Wheat Res 5: 55-58.

Kumar V, Khippal A, Singh J, Selvakumar R, Malik R, Kumar D, Kharub AS, Verma RPS and Sharma I (2014). Barley research in India: Retrospect \& prospects. J. Wheat Res. 6:1-20.

Mohammadi M, Jafarby JA, Khanzadeh H, Hosseinpur T, Mohammad MP, Roustaii M Hosni MH and Mohammadi P (2015). Stability of grain yield of durum wheat genotypes by AMMI model. Agriculture \& Forestry, Podgorica. 61: 181-193.

Mohammadi R, Roostaei M, Ansari Aghaee M and Amri M (2010). Relationships of phenotypic stability measures for genotypes of three cereal crops. Can. J. Plant Sci. 90: 819-830.

Mortazavian SMM, Nikkhah HR, Hassani FA, Sharif-al-Hosseini M, Taheri M and Mahlooji M (2014). GGE biplot and AMMI analysis of yield performance of barley genotypes across different environments in Iran Jour. Agr. Sci. Tech. 16: 609-622.

Purchase JL, Hatting H and Vandeventer CS (2000). Genotype $\times$ environment interaction of winter wheat (Triticum aestivum L.) in South Africa: Stability analysis of yield performance. South African Journal of Plant and Soil. 17: 101-107. 
Sabaghnia N, Sabaghpour SH and Dehghani H (2008). The use of an AMMI model and its parameters to analyse yield stability in multi-environment trials. J. Agric. Sci. 146: 571-581.

Sabaghnia N, Mohammadi M and Karimizadeh R (2012). The evaluation of Genotype $\times$ environment interaction of durum wheat's yield using of the AMMI model. Agriculture and Forestry 55: 5-21.

Silveira LCI, Kist V, Paula TOM, Barbosa MHP, Peternelli LA, Daros E (2013). AMMI analysis to evaluate the adaptability and phenotypic stability of sugarcane genotypes. Scientia Agricola. 70: 27-32.

Verma RPS, Kharub AS, Kumar D, Sarkar B, Selvakumar R, Singh R, Malik R, Kumar R and Sharma I(2011). Fifty years of coordinated barley research in India. Directorate of Wheat Research, Karnal-132001. Research Bulletin No. 27: 46.

VSN International (2014). GenStat for Windows 17th Edition. VSN International, Hemel Hempstead, UK.

Zhang Z, Lu C and Xiang ZH (1998). Analysis of variety stability based on AMMI model. Acta Agron. Sin. 24: 304-309. 